\title{
Catalysis at the Sub-Nanoscale: Complex CO Oxidation Chemistry on a Few Au Atoms
}

\author{
Nima Nikbin ${ }^{a}$, Natalie Austin ${ }^{b}$, Dionisios G. Vlachos ${ }^{a,{ }^{*}}$, Michail Stamatakis ${ }^{c,}$ and Giannis \\ Mpourmpakis, ${ }^{b *}$
}

${ }^{a}$ Department of Chemical and Biomolecular Engineering, University of Delaware, Newark, Delaware 19716, USA

${ }^{b}$ Department of Chemical Engineering, University of Pittsburgh, Pittsburgh, Pennsylvania 15621, USA

${ }^{c}$ Department of Chemical Engineering, University College London, Torrington Place, London WC1E 7JE, UK

\begin{abstract}
$\mathrm{Au}$ has been widely used as jewelry since ancient times due to its bulk, chemically inert properties. During the last three decades, nanoscale $\mathrm{Au}$ has attracted remarkable attention and has been shown to be an exceptional catalyst, especially for oxidation reactions. Herein, we elucidate a puzzle in catalysis by using multiscale computational modeling: the experimentally observed "magic number" CO oxidation catalytic behavior of subnanoscale Au clusters. Our results demonstrate that support effects (cluster charging), symmetry-induced electronic effects on the clusters, catalyst reconstruction, competing chemical pathways and formation of carbonate contribute to the marked differences in the observed catalytic behavior of $\mathrm{Au}_{\mathrm{n}}{ }^{-}$clusters with $\mathrm{n}=6,8$ and 10 atoms. This is the first demonstration of multiscale simulations on subnanoscale catalysts unraveling magic number activity for the $\mathrm{CO}$ oxidation reaction on $\mathrm{Au}$.
\end{abstract}

\section{Keywords}

DFT, kinetic Monte Carlo, charge, metal-oxide, support effects

*Corresponding authors: gmpourmp@pitt.edu, m.stamatakis@ucl.ac.uk, vlachos@udel.edu 


\section{Introduction}

$\mathrm{Au}$ is a remarkable metal with unique catalytic properties. It exhibits high activity at the nanoscale $\mathrm{e}^{1-3}$, whereas it is inert as bulk material ${ }^{4}$. Because of these unique properties, Au has found applications at both these extreme materials scales. Historically, it has been used as jewelry ${ }^{5}$ since ancient times due to its ability to prevent corrosion in bulk and maintain its bright color. The properties of $\mathrm{Au}$ at the nanoscale have recently been revealed with the explosive growth of nanotechnology. Nanoscale $\mathrm{Au}^{6-9}$ finds tremendous applications ranging from drug delivery ${ }^{10}$ in medicine to hydrogen production ${ }^{2}$ and energy generation.

Focusing on the catalytic applications of $\mathrm{Au}$ and specifically on the relatively simple $\mathrm{CO}$ oxidation reaction $\left(\mathrm{CO}+1 / 2 \mathrm{O}_{2} \rightarrow \mathrm{CO}_{2}\right)$, Haruta first showed that $\mathrm{Au}$ nanoparticles ${ }^{11}$ exhibit exceptional reactivity even at low temperatures ${ }^{12-17}$. These active Au nanoparticles are usually supported on metal-oxide surfaces ${ }^{3,18-20}$. Despite the large volume of work focused on the CO oxidation on $\mathrm{Au}$ in the last $\sim 30$ years, there is still much debate regarding the reaction mechanism $^{21}$. This is due to a large number of factors influencing the catalytic activity, such as the effect of the support, the Au particle size, and the presence of quantum effects in subnanometer catalysts. An emerging consensus is that under-coordinated sites on Au nanoparticles are the active sites for oxidation chemistry ${ }^{22-25}$. The Au nanoparticle sites on the metal-support interface which have been experimentally shown to be catalytically active $e^{26,27}$ can be also considered as under-coordinated sites.

According to this consensus about $\mathrm{Au}$, which suggests "the smaller the size, the higher the activity per site", we would expect all sub-nanometer, molecular size catalysts to be the most catalytically active. However, $\mathrm{CO}$ oxidation experiments involving small $\mathrm{Au}_{\mathrm{n}}$ clusters $(\mathrm{n}=2-20$ atoms, $<1 \mathrm{~nm}$ diameter) soft-landed on an O-defective $\mathrm{MgO}$ support ${ }^{28-30}$, revealed "magic number" catalytic behavior. The most active clusters were the $\mathrm{Au}_{8}{ }^{29}, \mathrm{Au}_{18}$ and $\mathrm{Au}_{20}$. The activity was attributed to the negative charge transferred from the support-vacancy to the clusters which activates $\mathrm{O}_{2}$ adsorption ${ }^{28,29}$. Previous work has proposed that $\mathrm{O}_{2}$ binds strongly on Au clusters with an odd number of electrons ${ }^{31,32}$. As a result, negatively charged Au clusters with an even number of $\mathrm{Au}$ atoms are expected to show increased activity because, in addition to having lowcoordinated sites, they also exhibit a preferred electronic configuration for $\mathrm{O}_{2}$ adsorption and activation $^{33}$. This magic number behavior, particularly illustrated by Arenz et $\mathrm{al}^{30}$, is most 
probably generic of sub-nanometer catalysis well beyond $\mathrm{Au}$ and remains an elusive field of catalytic science ${ }^{2,34,35}$.

In this work we use first-principles-based multiscale modeling to demonstrate that the $\mathrm{CO}$ oxidation activity of subnanometer $\mathrm{Au}$ is controlled by rather complicated physicochemical processes: charge transfer, different catalyst shapes, cluster reconstruction, electronic density on the catalyst, binding configuration of adsorbates and production of carbonate species can contribute towards the magic number catalytic behavior on $\mathrm{Au}$. Important enough, this work demonstrates the impact of a multiscale theoretical framework, linking ab-initio calculations with statistical mechanics, which enables us to access experimental length and time scales of complex catalytic systems.

\section{Computational Methods}

The support $(\mathrm{MgO})$ effects on the Au clusters (charge) were calculated at the BP86/def$\mathrm{sv}(\mathrm{p})$ level and default effective core pseudopotentials (def-ecp) were included for Au atoms, using the RI (resolution of identity) approximation as implemented in Turbomole $6.5^{36}$. The perfect $\mathrm{MgO}$ support consists of 112 atoms, $\mathrm{Mg}_{56} \mathrm{O}_{56}$, whereas the ones with an $\mathrm{O}$ vacancy consist of one atom less $\left(\mathrm{Mg}_{56} \mathrm{O}_{55}\right)$. In these calculations, the $\mathrm{MgO}$ was first fully optimized and then, when the clusters $\left(\mathrm{Au}_{6}, \mathrm{Au}_{8}\right.$ and $\left.\mathrm{Au}_{10}\right)$ were supported, the $\mathrm{MgO}$ coordinates were kept frozen and the clusters were allowed to fully relax on the $\mathrm{MgO}$ surface. Having identified a charge transfer from the support to the clusters, we removed the clusters from the support and we thoroughly investigated the $\mathrm{CO}$ oxidation reaction mechanisms on every possible site of the negatively charged clusters $\left(\mathrm{Au}_{6}^{-}, \mathrm{Au}_{8}{ }^{-}\right.$and $\left.\mathrm{Au}_{10}{ }^{-}\right)$at the B3LYP/LANL2DZ level of approximation, using the Gaussian 09 software package ${ }^{37}$. This combination of method and basis set has been successfully used to investigate the CO oxidation mechanism on Au clusters ${ }^{38-40}$. All reaction pathways were first mapped by scanning the potential energy surface of the reaction coordinate. The energy maximum found along the reaction coordinate was fully relaxed to a saddle point in order to locate the actual transition state. All transition states and local minima were obtained by full optimizations and verified by vibrational frequency and Intrinsic Reaction Coordinate (IRC) calculations.

The data from the aforementioned calculations served as input to Zacros, ${ }^{41}$ our in-house Fortran implementation of the graph-theoretical kinetic Monte Carlo (KMC) simulation 
framework $^{42,}{ }^{43}$. This input consists of a lattice structure, an energetics model, a reaction mechanism, and finally, the conditions of the simulation along with control parameters such as the frequency of sampling/reporting etc. Three planar lattices were thus used to represent the top and bridge sites of the Au nanoclusters, as shown in Figure 1.

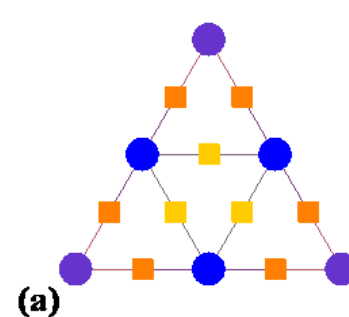

(b)
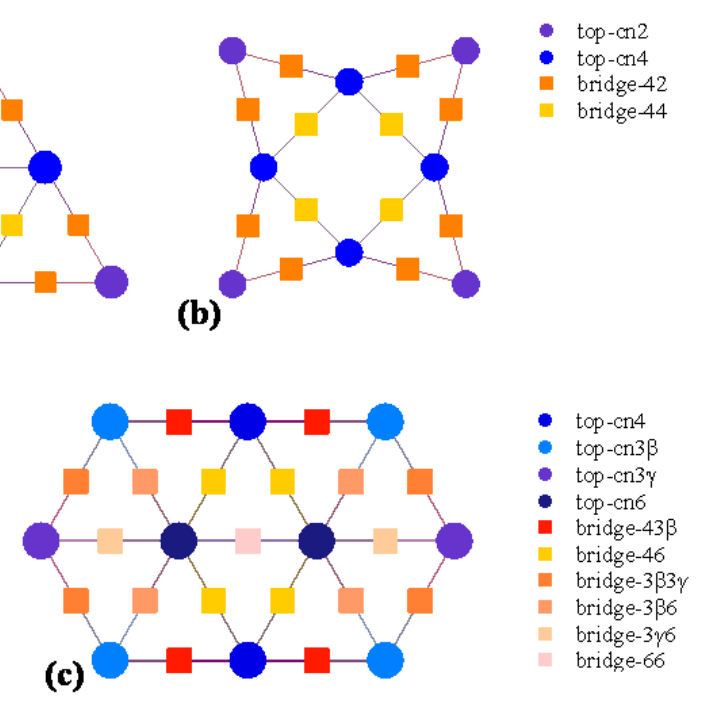

Figure 1: Lattice structures for the three Au nanoclusters, denoting the sites that were taken into account in the models.

The energetics model contained the binding energies of all intermediates to the pertinent sites (top and bridge), and explicitly accounted for multi-site species, such as carbonate. Moreover, strong repulsive interactions between $\mathrm{O}_{2}$ adsorbates were incorporated into the energetics model, since the DFT calculations showed that a maximum of one oxygen molecule can bind to any of these clusters. All energetics models are presented in detail in the supplementary material.

The reaction mechanism for each of the three nanoclusters contained the adsorption/desorption, diffusion and surface and Eley-Rideal reaction elementary steps computed via DFT. Transition state theory approximations were used to calculate the rate constants (see supplementary material of Ref. ${ }^{44}$ ). Within the KMC framework, event occurrence is treated as a Poisson stochastic process, and to simulate the occurrence of the elementary events, Zacros utilizes a rejection-free algorithm with local updating of the propensities ${ }^{45}$. In view of the stochastic nature of $\mathrm{KMC}$, ensembles of 100 (for $\mathrm{Au}_{6}{ }^{-}$) or 10 clusters (for $\mathrm{Au}_{8}{ }^{-}$and $\mathrm{Au}_{10}{ }^{-}$) were used to investigate the kinetics. All simulations were performed at a temperature of $250 \mathrm{~K}$ for an 
isomolar mixture of $\mathrm{CO}$ and $\mathrm{O}_{2}$ at 1 bar. It should be noted that we have successfully applied this methodology to the $\mathrm{MgO}$ supported $\mathrm{Au}_{6}$ clusters very recently ${ }^{46}$, by investigating support effects and reaction mechanism with quantum mechanical calculations (RI-BP86 and B3LYP level of approximation respectively) and importing the DFT-calculated reaction energetics into graphtheoretical kinetic Monte Carlo simulations.

\section{Results}

Au clusters up to the $\mathrm{Au}_{13}$ size (consisting of 13 atoms) exhibit planar geometries. When these clusters are supported on $\mathrm{MgO}$ with $\mathrm{O}$ vacancies they are charged negatively ${ }^{29,46}$. Each $\mathrm{O}$ vacancy can give electron density to the clusters approximately close to one electron (-0.8 to -1.4 $|\mathrm{e}|)$, whereas, when the clusters are supported on a perfect $\mathrm{MgO}$ the charge that is transferred is significantly smaller (-0.2 to $-0.3|\mathrm{e}|)$. This behavior is illustrated in Figure 2, where we show the interactions of $\mathrm{Au}_{6}, \mathrm{Au}_{8}$ and $\mathrm{Au}_{10}$ with $\mathrm{MgO}$ and the total charge transferred from the support.

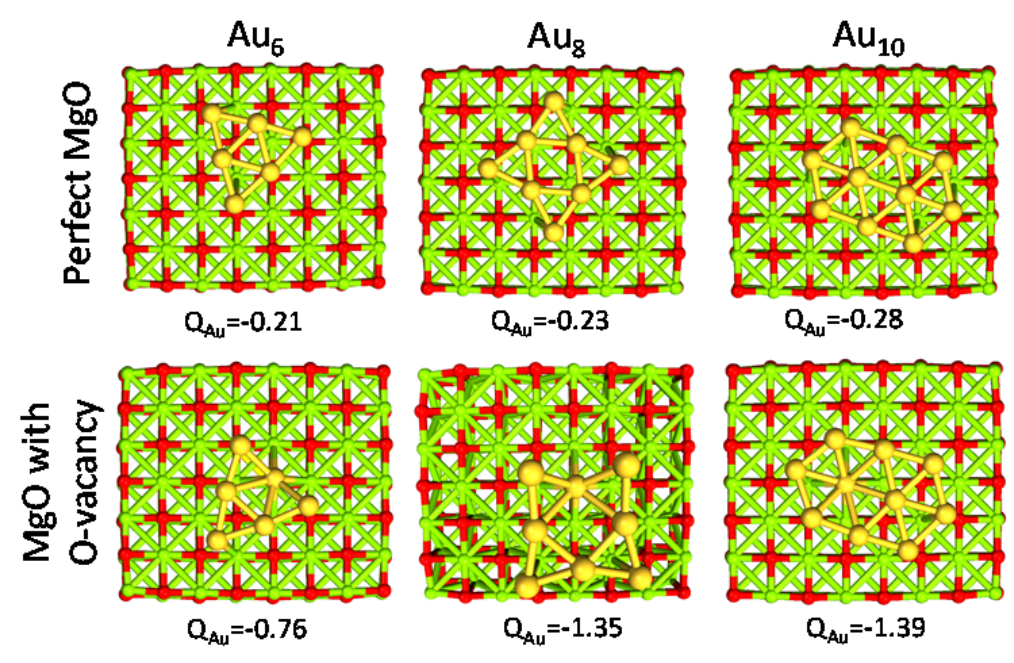

Figure 2: $\mathrm{Au}_{6}, \mathrm{Au}_{8}$ and $\mathrm{Au}_{10}$ clusters interacting with a perfect $\mathrm{MgO}$ support and a support with an $\mathrm{O}$ vacancy. The total Natural Bond Orbital (NBO) charge transferred from the support to the clusters is shown at the bottom of each graph.

This electron density can be transferred to the clusters, even when the clusters are $20 \AA$ away from the support vacancy ${ }^{47}$. Clusters with even number of atoms will end up with an odd number of electrons after this electron transfer from the support vacancy, which will favor $\mathrm{O}_{2}$ adsorption. In Figure 3 we present the HOMO and LUMO (highest occupied and lowest unoccupied molecular) orbitals of the $\mathrm{Au}_{6}^{-}, \mathrm{Au}_{8}{ }^{-}$and $\mathrm{Au}_{10}{ }^{-}$clusters (catalysts of interest). $\mathrm{CO}\left(\mathrm{O}_{2}\right)$ is an 
electron donor (acceptor) molecule and preferentially interacts with sites on the clusters where the LUMO (HOMO) orbitals are localized. The first complexity in these molecular-sized catalysts arises from the fact that the HOMO and LUMO orbitals are not necessarily localized on the lowest coordinated sites of the clusters ${ }^{32}$. As a result, the lowest coordinated sites are not necessarily the strongest adsorption sites on the catalysts. This is exemplified in the case of $\mathrm{Au}_{10}{ }^{-}$ where the HOMO orbital, which is semi-occupied, is localized primarily on the Au atoms that exhibit coordination number 4 (and to their first neighbors with coordination number 3 ) and not explicitly to the lowest coordinated sites of the cluster (with coordination 3). Thus, molecular oxygen adsorbs on $\mathrm{Au}_{10}{ }^{-}$cluster with a bidentate configuration on top of the $\mathrm{Au}$ atoms where the HOMO orbital is localized (see initial state in Figure 4(d) vide-infra).

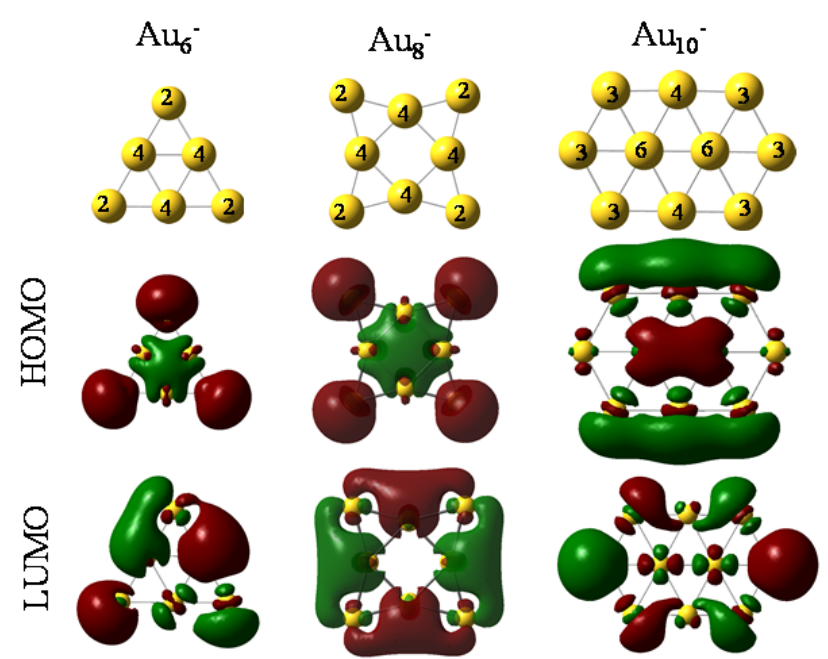

Figure 3: Geometries and molecular orbital density of $\mathrm{Au}_{6}{ }^{-}, \mathrm{Au}_{8}{ }^{-}$and $\mathrm{Au}_{10}{ }^{-}$clusters. The numbers on the clusters represent the coordination of each $\mathrm{Au}$ atom. The highest occupied (HOMO) and the lowest unoccupied molecular orbitals (LUMO) of each cluster are illustrated. The HOMO orbitals are semi-occupied in every case (spin multiplicity doublet).

Next we calculated the detailed energetics of the CO oxidation reaction (step 1: $\mathrm{CO}^{*}+$ $\mathrm{O}_{2}{ }^{*} \rightarrow \mathrm{CO}_{2}+\mathrm{O}^{*}$ and step 2: $\mathrm{CO}^{*}+\mathrm{O}^{*} \rightarrow \mathrm{CO}_{2}$ ) on these three clusters, by taking into consideration every possible adsorption configuration of $\mathrm{CO}$ and $\mathrm{O}_{2}$. As a result, we calculated approximately 160 catalytic events which include: adsorption, reaction, and desorption of all the gas species. Details about the calculations and reaction energy pathways appear in the supporting information file. In Figure 4 (a) - (c), we selectively present the first step of the CO oxidation reaction from a 4-center $\mathrm{CO}-\mathrm{O}_{2}$ adsorbed intermediate that has been reported to be the rate 
limiting step in the CO oxidation reaction ${ }^{38}$. These specific reaction steps on each of the three clusters appear to control their reactivity, but for completely different reasons as we will show next with our kinetic Monte Carlo (KMC) simulations. Just by comparing the density functional theory $(\mathrm{DFT})$ calculated reaction barriers on $\mathrm{Au}_{6}{ }^{-}=16.2, \mathrm{Au}_{8}{ }^{-}=14.8$, and $\mathrm{Au}_{10}{ }^{-}=13.2(\mathrm{kcal} / \mathrm{mol})$ presented in Figure 4 (a)-(c), one could conclude that $\mathrm{Au}_{10}{ }^{-}$appears to be the most active cluster among the three and the activity is a monotonic function of size, in contradiction to experiments. In $\mathrm{Au}_{6}{ }^{-}$, the product of the first $\mathrm{CO}$ oxidation reaction step is carbonate $\left(\mathrm{CO}_{3}\right)$ and not $\mathrm{CO}_{2}$. Carbonate binds very strongly on the catalyst and its dissociation to a $\mathrm{CO}_{2}$ molecule is highly unfavorable ${ }^{46}$. A unique reaction step to the $\mathrm{Au}_{10}{ }^{-}$case is the $\mathrm{O}_{2}$ "tilting" presented in Figure 4 (d). $\mathrm{O}_{2}$ preferentially interacts with the cluster with the bidentate configuration due to electronic reasons we discussed in the previous paragraph. In this configuration, $\mathrm{O}_{2}$ has to tilt in order to react with $\mathrm{CO}$ through the 4-center intermediate, which requires activation energy of 10.7 $\mathrm{kcal} / \mathrm{mol}$.

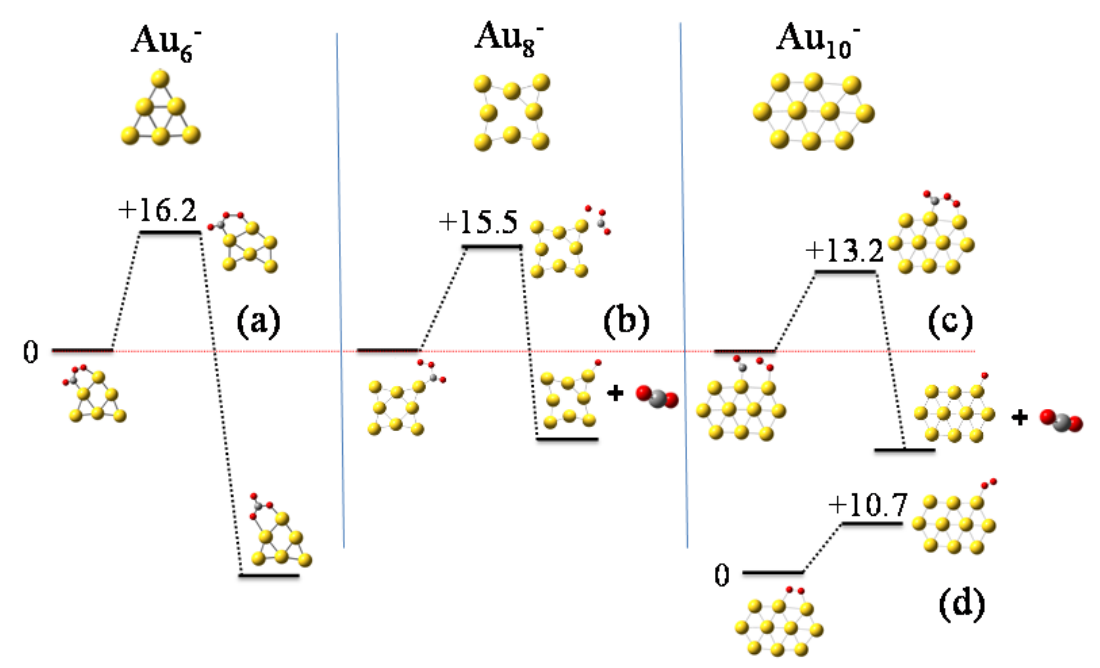

Figure 4: Key reactions controlling catalytic activity on the clusters among 160 total reaction steps investigated by quantum mechanical theoretical calculations: (a) - (c) first step of $\mathrm{CO}$ oxidation mechanism involving a CO$\mathrm{O}_{2}$ four-center intermediate and on $\mathrm{Au}_{6}^{-}, \mathrm{Au}_{8}{ }^{-}$and $\mathrm{Au}_{10}{ }^{-}$, respectively, and $\mathrm{O}_{2}$ tilting step on $\mathrm{Au}_{10}{ }^{-}$(d).

The reason that carbonate forms on $\mathrm{Au}_{6}{ }^{-}$is because the cluster has two almost isoenergetic $(\Delta \mathrm{E} \sim 2 \mathrm{kcal} / \mathrm{mol})$ geometries of $\mathrm{D}_{3 \mathrm{~h}}$ and $\mathrm{D}_{2 \mathrm{~h}}$ symmetries and can restructure with a very small transformation barrier of $\sim 4 \mathrm{kcal} / \mathrm{mol}$. Freezing the cluster in its initial geometry during reaction pathway calculations would result in the formation of $\mathrm{CO}_{2}$ and not carbonate. Interestingly, as we show in Figure 5, a similar transition from a $\mathrm{D}_{4 \mathrm{~h}}$ to a stable geometry of 
lower symmetry (e.g., $\mathrm{D}_{2 \mathrm{~h}}$ ) does not exist in $\mathrm{Au}_{8}{ }^{-}$neither on the neutral states of these two clusters $\left(\mathrm{Au}_{6}{ }^{0}, \mathrm{Au}_{8}{ }^{0}\right)$. Even though it is possible that reconstruction happens on $\mathrm{Au}_{8}{ }^{-}$catalyst under reaction conditions (e.g., adsorbate-induced, see detailed reaction mechanism presented in Figure 7(b)), we show that at least for the specific elongation coordinate (similar to the one causing reconstruction of $\mathrm{Au}_{6}$ ) shown in Figure 5 the cluster is stable (i.e., symmetry-induced reconstruction does not occur).



Figure 5: Potential energy curves of $\mathrm{Au}_{6}$ (squares) and $\mathrm{Au}_{8}$ (circles) catalyst restructuring in neutral (closed symbols), and negative (opened symbols) charge states. The elongation coordinates are shown in the upper right.

To investigate the reactivity of the three different nanoclusters for the $\mathrm{CO}$ oxidation we performed first-principles KMC simulations ${ }^{44}$ using our ab-initio data as input and the Zacros software implementation of the Graph-Theoretical KMC method ${ }^{42,43}$. By calculating the number of $\mathrm{CO}_{2}$ molecules produced per site per time, we estimated the turnover frequencies (TOFs) for each $\mathrm{Au}$ structure, and by analyzing the statistics of occurrence of each elementary step, we identified the dominant pathways for each structure. The results are presented in Figures 6-8. 

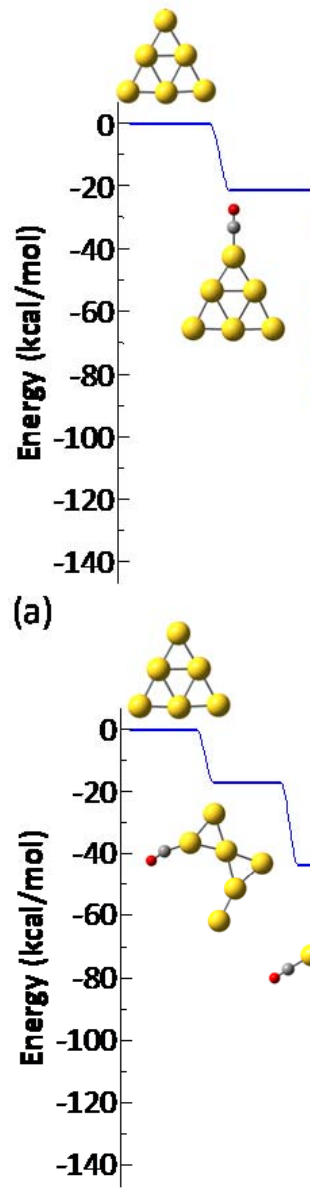

(b)
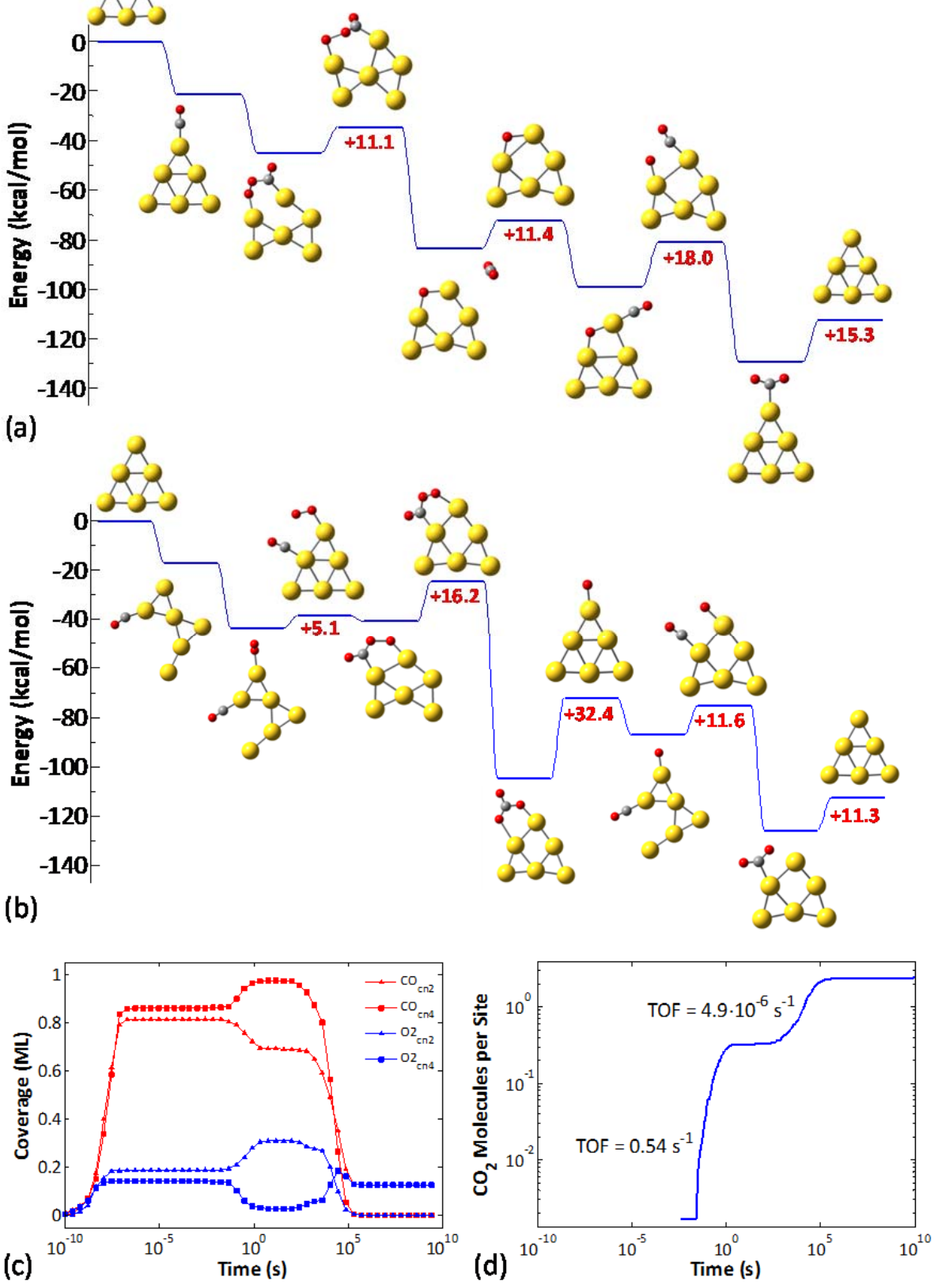

Figure 6: (a) Unhindered $\mathrm{CO}$ oxidation pathway on the $\mathrm{Au}_{6}{ }^{-}$nanocluster, with $\mathrm{CO}$ initially adsorbing on a $\mathrm{CN} 2$ site and $\mathrm{O}_{2}$ on a $\mathrm{CN} 4$ site. (b) The pathway resulting to poisoning on the $\mathrm{Au}_{6}{ }^{-}$nanocluster; here, $\mathrm{CO}$ initially adsorbs on a $\mathrm{CN} 4$ site and $\mathrm{O}_{2}$ on a $\mathrm{CN} 2$ site. (c) Average coverages of $\mathrm{CO}$ and $\mathrm{O}_{2}$ on the $\mathrm{CN} 2$ and $\mathrm{CN} 4$ sites of the $\mathrm{Au}_{6}{ }^{-}$ nanocluster, calculated from an ensemble of 100 clusters (100 KMC runs with different random seed). (d) Average number of $\mathrm{CO}_{2}$ molecules produced per cluster in an ensemble of 100 clusters. After exhibiting some transient activity $\mathrm{Au}_{6}{ }^{-}$is poisoned (see also Ref. ${ }^{46}$ ). 
For $\mathrm{Au}_{6}{ }^{-}$our previous work identified two possible pathways depending on the initial binding sites of $\mathrm{O}_{2}$ and $\mathrm{CO}$ (Figure $6 \mathrm{a}, \mathrm{b}$ ), ${ }^{46}$ both of which are active in different timescales: the contribution of each pathway is revealed by Figure $6 \mathrm{c}$, which depicts the $\mathrm{CO}$ and $\mathrm{O}_{2}$ coverages on the different site types of the $\mathrm{Au}_{6}{ }^{-}$cluster (all data are averages over an ensemble of $100 \mathrm{KMC}$ runs), as well as Figure $6 \mathrm{~d}$ which shows the $\mathrm{CO}_{2}$ molecules produced per site. Evidently, there are two phases of transient activity, followed by the eventual poisoning of the cluster. Thus, initially, $\mathrm{CO}$ and $\mathrm{O}_{2}$ are randomly adsorbing on the $\mathrm{CN} 2$ and $\mathrm{CN} 4$ sites, resulting in approximately same coverages for both site types. At timescales of around $10^{-2} \mathrm{~s}$, the CO oxidation reaction initiates and proceeds via the first pathway (Figure 6a), as evidenced by the depletion of $\mathrm{CO}$ on $\mathrm{CN} 2$ and $\mathrm{O}_{2}$ on CN4. Subsequently, on the timescale of $1 \mathrm{~s}$, the second pathway becomes active (Figure 6b). This delay can be attributed to the slightly higher barriers thereof: $5.1 \mathrm{kcal} / \mathrm{mol}$ for the 4-center intermediate formation, and $16.2 \mathrm{kcal} / \mathrm{mol}$ for the conversion of the latter to $\mathrm{CO}_{3}$ (in the first pathway the higher barrier is $18 \mathrm{kcal} / \mathrm{mol}$ for the final $\mathrm{O}+\mathrm{CO}$ reaction). $\mathrm{CO}_{3}$ formation via the $2^{\text {nd }}$ pathway competes with the $1^{\text {st }}$ pathway, this is why we still see $\mathrm{CO}_{2}$ formation even well after $1 \mathrm{~s}$. Note that the plateau in the $\mathrm{CO}_{2}$ produced in the in the log-log diagram of Figure $6 \mathrm{~d}$ is due to the distortion of timescales in the logarithmic scale: short timescales are magnified and long timescales shrink. Plotted in linear scale, it is apparent that $\mathrm{CO}_{2}$ formation does not cease temporarily to resume with higher rates later; it proceeds continuously, but with a much lower rate after about $1 \mathrm{~s}$. Eventually, the catalyst gets poisoned by $\mathrm{CO}_{3}$ : the non-zero average coverages for $\mathrm{O}_{2}$ at $\mathrm{CN} 4$ and $\mathrm{CO}$ at $\mathrm{CN} 2$ are due to the nanoclusters with $2 \mathrm{CO}_{3}$ molecules in the opposite sides of the triangular $\mathrm{Au}_{6}$ structure.

$\mathrm{Au}_{8}{ }^{-}$on the other hand was found to exhibit the highest reactivity among the three clusters investigated (Figure 7). The reaction proceeds via the formation and decomposition of a four-center $\mathrm{CO}^{\cdots} \mathrm{O}_{2}$ intermediate. Two pathways contribute to the overall activity: the first one involves a monodentate binding configuration of the four-center intermediate, whose decomposition according to step (b) of Figure 3 is rate limiting. The second pathway implicates a bidentate configuration and entails adsorbate-induced cluster reconstruction. The latter was taken into account implicitly in the energetics of the reaction steps. Notice that this cluster reconstruction is induced by the adsorption of the reacting species and not by the symmetry of the cluster as we showed in Figure 5. The average turnover frequency (TOF) of this cluster was estimated to $0.73 \mathrm{~s}^{-1}$ and was the highest among those of the Au nanoclusters considered. 

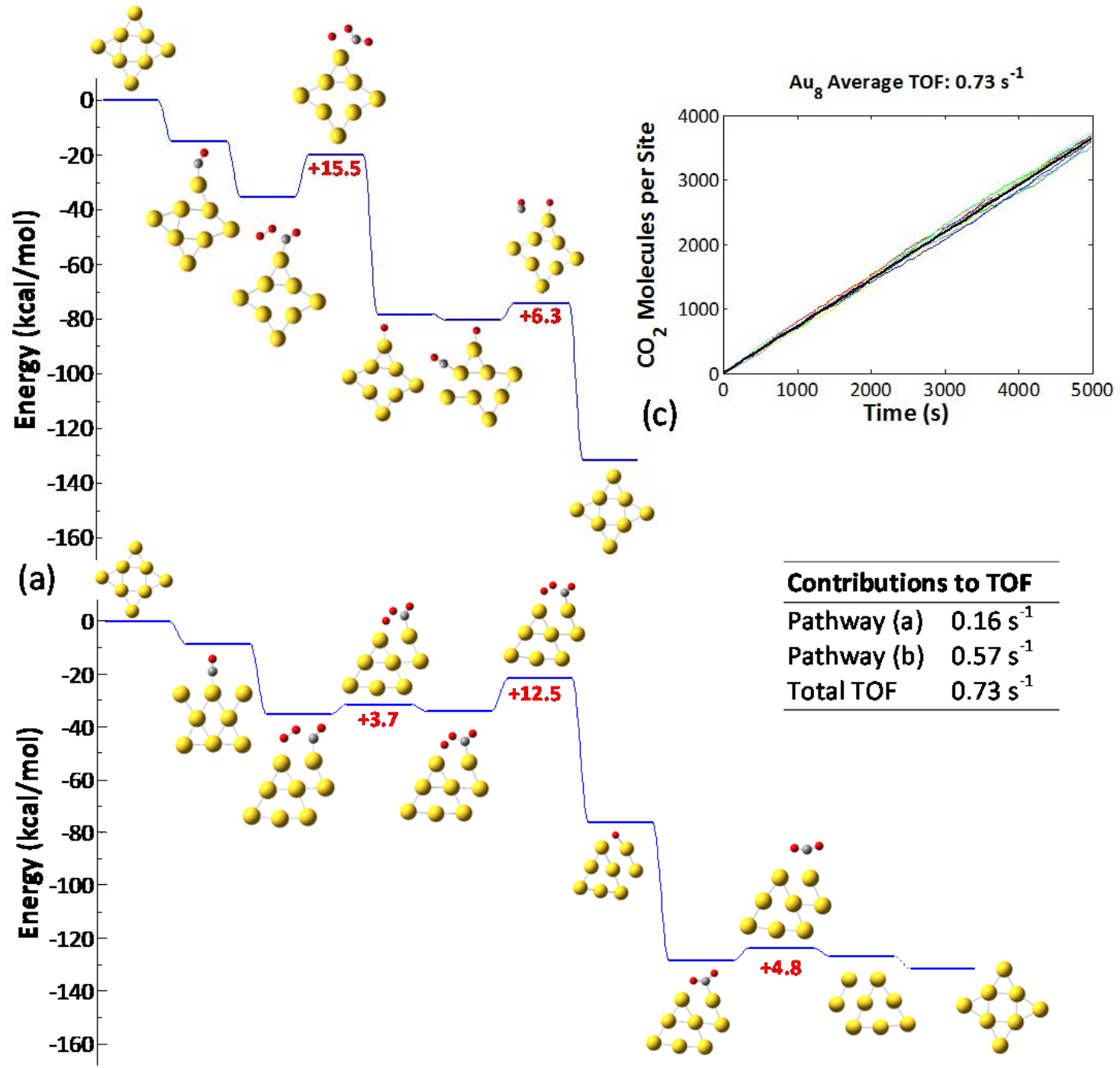

(b)

Figure 7: (a, b) Kinetically preferred pathways on $\mathrm{Au}_{8}{ }^{-}$. (c) Number of $\mathrm{CO}_{2}$ molecules produced per site in an ensemble of 10 clusters; the average number is denoted by the thick black line. The contributions of the two pathways on the overall TOF are noted.

In the case of $\mathrm{Au}_{10}{ }^{-}$, bidentate $\mathrm{O}_{2}$ species were found to be significantly more stable than monodentate ones (by about $10 \mathrm{kcal} / \mathrm{mol}$ ); however, the former are inactive due to the high barriers of the reaction with $\mathrm{CO}^{38}$. Thus, on the $\mathrm{Au}_{10}{ }^{-}$structure, the chemistry proceeds via the tilting of bidentate $\mathrm{O}_{2}$ to a monodentate (active) configuration (Figure 8a), followed by the 
reaction between $\mathrm{O}_{2}$ and adsorbed $\mathrm{CO}$, which has an activation energy on the order of 10 $\mathrm{kcal} / \mathrm{mol}$ (the exact values depend on the actual sites occupied and are shown in the supplementary information file). The sequence of these two steps is rate-limiting for the $\mathrm{CO}$ oxidation reaction on $\mathrm{Au}_{10}$. The TOF of this cluster is approximately $0.02 \mathrm{~s}^{-1}$ (Figure 8b), which is lower than that of $\mathrm{Au}_{8}{ }^{-}$by more than an order of magnitude and in qualitative agreement with experimental observations $\left(\mathrm{Au}_{6}{ }^{-} \text {inert, } \mathrm{Au}_{8}{ }^{-} \text {active, } \mathrm{Au}_{10}{ }^{-} \text {less active than } \mathrm{Au}_{8}{ }^{-}\right)^{28-30}$.



Figure 8: (a) Representative kinetically favored $\mathrm{CO}$ oxidation pathway on $\mathrm{Au}_{10} 0^{-}$. (b) Number of $\mathrm{CO}_{2}$ molecules produced per site in an ensemble of 10 clusters; the average number is denoted by the thick black line.

As a final note, this work highlights that more sophisticated models need to be developed to correlate the catalytic activity with electronic properties of the clusters, which in turn arise from their geometric characteristics ${ }^{48,49}$. In addition, the stability of the supported clusters plays an important role on their catalytic behavior. Incorporation of ligands on Au clusters could improve their stability by limiting cluster agglomeration, while maintaining $\mathrm{CO}$ oxidation activity ${ }^{1}$. However, the reaction mechanisms on these clusters are expected to completely change in the presence of ligands. 


\section{Conclusions}

Using multiscale modeling simulations we investigated the $\mathrm{CO}$ oxidation behavior of subnanosized Au catalysts that consist of a few metal atoms. This study unravels a high degree of complexity in the catalytic behavior of Au clusters: competing physicochemical phenomena on the catalyst result to the experimentally observed "magic number" $\mathrm{CO}$ oxidation activity. Subnanocatalysis, despite being attractive due to the atomic-level precision of the catalysts and its often unprecedented performance, remains an empirical field. Simulations, such as the ones presented here, can significantly advance our understanding and lead to better catalysts and processes.

\section{Acknowledgements}

G.M. and N.A. would like to acknowledge computational support from the Center for Simulation and Modeling (SAM) and start-up funding from the University of Pittsburgh. M.S. acknowledges the use of the UCL Legion High Performance Computing Facility (Legion@UCL), and associated support services, in the completion of the KMC simulations of this work. The material on $\mathrm{CO}$ oxidation on $\mathrm{Au}$ is also based upon work financially supported by a Marie Curie International Outgoing Fellowship within the 7th European Community Framework Programme. The work conducted at Delaware was supported by Grant No. DESC0010549 from the (U.S.) Department of Energy (DOE).

Author Contributions: N.N., N.A., M.S. and G.M. performed the calculations. G.M., M.S. and D.G.V. conceptualized the study and carried out the advising. G.M. and M.S. wrote the manuscript and all authors edited and proofread the paper.

\section{References}

1. O. Lopez-Acevedo, K. A. Kacprzak, J. Akola and H. Hakkinen, Nature Chemistry, 2010, 2, 329-334.

2. Q. Fu, H. Saltsburg and M. Flytzani-Stephanopoulos, Science, 2003, 301, 935-938.

3. M. Valden, X. Lai and D. W. Goodman, Science, 1998, 281, 1647-1650.

4. B. Hammer and J. K. Norskov, Nature, 1995, 376, 238-240.

5. J. Quilter, Science, 1998, 282, 1058-1059.

6. G. C. Bond and D. T. Thompson, Catalysis Reviews-Science and Engineering, 1999, 41, 319-388.

7. G. Mpourmpakis, S. Caratzoulas and D. G. Vlachos, Nano Letters, 2010, 10, 3408-3413. 
8. P. D. Jadzinsky, G. Calero, C. J. Ackerson, D. A. Bushnell and R. D. Kornberg, Science, 2007, 318, 430-433.

9. $\quad$ Y. G. Sun and Y. N. Xia, Science, 2002, 298, 2176-2179.

10. E. Boisselier and D. Astruc, Chem. Soc. Rev., 2009, 38, 1759-1782.

11. M. Haruta, T. Kobayashi, H. Sano and N. Yamada, Chemistry Letters, 1987, 16, 405-408.

12. T. S. Kim, J. D. Stiehl, C. T. Reeves, R. J. Meyer and C. B. Mullins, Journal of the American Chemical Society, 2003, 125, 2018-2019.

13. W. S. Epling, G. B. Hoflund, J. F. Weaver, S. Tsubota and M. Haruta, Journal of Physical Chemistry, 1996, 100, 9929-9934.

14. S. D. Lin, M. Bollinger and M. A. Vannice, Catalysis Letters, 1993, 17, 245-262.

15. B. Schumacher, V. Plzak, M. Kinne and R. J. Behm, Catalysis Letters, 2003, 89, 109114.

16. J. D. Stiehl, T. S. Kim, S. M. McClure and C. B. Mullins, Journal of the American Chemical Society, 2004, 126, 13574-13575.

17. S. Tsubota, D. A. H. Cunningham, Y. Bando and M. Haruta, in Preparation of Catalysts Vi, 1995, vol. 91, pp. 227-235.

18. M. Haruta, Cattech, 2002, 6, 102-115.

19. R. Meyer, C. Lemire, S. K. Shaikhutdinov and H. Freund, Gold Bulletin, 2004, 37, 72124.

20. D. R. Rainer and D. W. Goodman, Journal of Molecular Catalysis a-Chemical, 1998, 131, 259-283.

21. M. C. Kung, R. J. Davis and H. H. Kung, Journal of Physical Chemistry C, 2007, 111, 11767-11775.

22. G. C. Bond, C. Louis and D. T. Thompson, Catalysis by Gold, Imperial College Press, 2006.

23. B. Hvolbaek, T. V. W. Janssens, B. S. Clausen, H. Falsig, C. H. Christensen and J. K. Norskov, Nano Today, 2007, 2, 14-18.

24. G. Mpourmpakis, A. N. Andriotis and D. G. Vlachos, Nano Letters, 2010, 10, 1041 1045.

25. I. N. Remediakis, N. Lopez and J. K. Norskov, Applied Catalysis a-General, 2005, 291, 13-20.

26. I. X. Green, W. Tang, M. Neurock and J. T. Yates, Jr., Science, 2011, 333, 736-739.

27. T. Fujitani and I. Nakamura, Angewandte Chemie-International Edition, 2011, 50, 10144-10147.

28. A. Sanchez, S. Abbet, U. Heiz, W. D. Schneider, H. Hakkinen, R. N. Barnett and U. Landman, Journal of Physical Chemistry A, 1999, 103, 9573-9578.

29. B. Yoon, H. Hakkinen, U. Landman, A. S. Worz, J.-M. Antonietti, S. Abbet, K. Judai and U. Heiz, Science, 2005, 307, 403-407.

30. M. Arenz, U. Landman and U. Heiz, ChemPhysChem, 2006, 7, 1871-1879.

31. G. Mills, M. S. Gordon and H. Metiu, Chemical Physics Letters, 2002, 359, 493-499.

32. S. Chretien, S. K. Buratto and H. Metiu, Curr. Opin. Solid State Mat. Sci., 2007, 11, $62-$ 75.

33. R. Pal, L. M. Wang, Y. Pei, L. S. Wang and X. C. Zeng, Journal of the American Chemical Society, 2012, 134, 9438-9445.

34. G. Li and R. C. Jin, Accounts Chem. Res., 2013, 46, 1749-1758. 
35. X. Guo, G. Fang, G. Li, H. Ma, H. Fan, L. Yu, C. Ma, X. Wu, D. Deng, M. Wei, D. Tan, R. Si, S. Zhang, J. Li, L. Sun, Z. Tang, X. Pan and X. Bao, Science, 2014, 344, 616-619.

36. R. Ahlrichs, M. Bar, M. Haser, H. Horn and C. Kolmel, Chemical Physics Letters, 1989, 162, 165-169.

37. M. J. T. Frisch, G. W.; Schlegel, H. B.; Scuseria, G. E.; Robb, M. A.; Cheeseman, J. R.; Scalmani, G.; Barone, V.; Mennucci, B.; Petersson, G. A.; Nakatsuji, H.; Caricato, M.; Li, X.; Hratchian, H. P.; Izmaylov, A. F.; Bloino, J.; Zheng, G.; Sonnenberg, J. L.; Hada, M.; Ehara, M.; Toyota, K.; Fukuda, R.; Hasegawa, J.; Ishida, M.; Nakajima, T.; Honda, Y.; Kitao, O.; Nakai, H.; Vreven, T.; Montgomery, Jr., J. A.; Peralta, J. E.; Ogliaro, F.; Bearpark, M.; Heyd, J. J.; Brothers, E.; Kudin, K. N.; Staroverov, V. N.; Kobayashi, R.; Normand, J.; Raghavachari, K.; Rendell, A.; Burant, J. C.; Iyengar, S. S.; Tomasi, J.; Cossi, M.; Rega, N.; Millam, J. M.; Klene, M.; Knox, J. E.; Cross, J. B.; Bakken, V.; Adamo, C.; Jaramillo, J.; Gomperts, R.; Stratmann, R. E.; Yazyev, O.; Austin, A. J.; Cammi, R.; Pomelli, C.; Ochterski, J. W.; Martin, R. L.; Morokuma, K.; Zakrzewski, V. G.; Voth, G. A.; Salvador, P.; Dannenberg, J. J.; Dapprich, S.; Daniels, A. D.; Farkas, Ö.; Foresman, J. B.; Ortiz, J. V.; Cioslowski, J.; Fox, D. J. Gaussian, Inc., Wallingford CT, 2009.

38. N. Nikbin, G. Mpourmpakis and D. G. Vlachos, Journal of Physical Chemistry C, 2011, $115,20192-20200$.

39. A. Prestianni, A. Martorana, F. Labat, I. Ciofini and C. Adamo, Journal of Physical Chemistry B, 2006, 110, 12240-12248.

40. T. Davran-Candan, A. E. Aksoylu and R. Yildirim, Journal of Molecular Catalysis aChemical, 2009, 306, 118-122.

41. M. Stamatakis, Zacros: Advanced Lattice-KMC simulation Made Easy, http://tinyurl.com/zacroskmc.

42. M. Stamatakis and D. G. Vlachos, Journal of Chemical Physics, 2011, 134, 214115.

43. J. Nielsen, M. d'Avezac, J. Hetherington and M. Stamatakis, J. Chem. Phys., 2013, 139, 224706.

44. M. Stamatakis and D. G. Vlachos, ACS Catal., 2012, 2, 2648-2663.

45. A. Chatterjee and D. G. Vlachos, Journal of Computer-Aided Materials Design, 2007, $14,253-308$.

46. M. Stamatakis, M. A. Christiansen, D. G. Vlachos and G. Mpourmpakis, Nano Letters, 2012, 12, 3621-3626.

47. K. McKenna, T. Trevethan and A. Shluger, Physical Review B, 2010, 82.

48. H. Li, L. E. Li and Y. D. Li, Nanotechnol. Rev., 2013, 2, 515-528.

49. J. Liu, K. S. Krishna, Y. B. Losovyj, S. Chattopadhyay, N. Lozova, J. T. Miller, J. J. Spivey and C. Kumar, Chem.-Eur. J., 2013, 19, 10201-10208. 